\title{
KEEPING COUNTRY: \\ A web-based approach to Indigenous outreach in cultural heritage management
}

\author{
Andrew Fairbairn ${ }^{1}$, Annie Ross ${ }^{1,2}$, Sean Ulm ${ }^{3}$, Stephen Nichols ${ }^{1,3}$ and Patrick Faulkner ${ }^{1}$
}

\begin{abstract}
Cultural heritage management (CHM) of Indigenous places is the dominant area of professional practice in Australian archaeology, yet relatively few Indigenous Australians take up a career in the sector. The internet is providing new and effective avenues for Indigenous outreach programmes. This paper describes a self-contained, web-enabled, freeto-user cultural heritage training programme designed in consultation with, and for the use of, Indigenous Australians. It includes a consideration of the potential and design requirements of web-delivered courses for more effectively introducing Indigenous communities to the professional CHM sector and thus achieving the long-term goal of increasing the participation of those communities in professional work.
\end{abstract}

\section{Introduction}

$\overline{\text { During the last decade, developer-funded cultural heritage }}$ management (CHM) has become the dominant area of archaeological professional practice in Australia, with Indigenous archaeology - the archaeology of Aboriginal and Torres Strait Islander peoples-a key focus of that work. While many Indigenous Australians participate in CHM work as community stakeholder representatives, relatively few participate as archaeological professionals. While the low proportion of Indigenous professionals matches levels found in other developed post-colonial nations (compare Ulm et al. 2013; Zeder 1997:13), the low level of participation does not reflect the prominence of Indigenous values in Australian $\mathrm{CHM}$ projects, the recognised ongoing significance of that cultural heritage for Indigenous Australians, or indeed the efforts that Australia's professional organisations (e.g. the Australian Archaeological Association [AAA], the Australian Association of Consulting Archaeologists Inc. [AACAI] and the Australian Indigenous Archaeologists' Association [AIAA]) have made to support Indigenous participation in archaeology (Perry 2010). In this paper we describe a new initiative in Indigenous outreach in Australian CHM education, using an open access, self-contained, web-based training course (Keeping Country) to both build capacity in CHM skills in Indigenous communities and to open routes to professional entry for those community members interested in advancing their professional career opportunities. We demonstrate the potential of internet delivery and open source-freely accessible, modifiable and distributablelearning management systems to provide the medium and

\footnotetext{
School of Social Science, The University of Queensland, St Lucia Qld 4072, Australia <a.fairbairn@uq.edu.au><p.faulkner@uq.edu.au>

${ }^{2}$ School of Geography, Planning and Environmental Management, The University of Queensland, St Lucia Old 4072, Australia <annie.ross@uq.edu.au>

${ }^{3}$ Department of Anthropology, Archaeology and Sociology, School of Arts and Social Sciences, James Cook University, PO Box 6811, Cairns Old 4870, Australia <sean.ulm@jcu.edu.au><snicholsdig@gmail.com>
}

the architecture for community outreach projects, especially in widely spread and remote Indigenous user groups.

\section{CHM in Australia}

Australia has a diverse and complex cultural heritage extending back 45,000-60,000 years (Hiscock 2008). This heritage is under unprecedented threat from large-scale economic development, including mineral extraction, population-driven housing expansion and construction of infrastructure. A key professional focus for Australia's archaeologists is CHM. Cultural heritage has been defined as 'the totality of forms of creativity—physical and non-physical—and the body of values through which, as part of its historical continuity, a people or nation reveals itself most clearly' (Makagiansar 1989:9). In this way, heritage incorporates both archaeological analyses of material components of the past and anthropological evaluations of intangible aspects of place, as well as past and present lifeways (Byrne 2005; Ellis 1994; Godwin 2005; Godwin and Weiner 2006; Prangnell et al. 2010). Although legislation generally privileges the tangible aspects of heritage (Ross 2010; Ross et al. 2010), heritage practitioners in Australia (as elsewhere, cf. King 2003) have heeded Indigenous peoples' calls for a wider contextualisation of the discipline (Fourmile 1996; Langford 1983). As a consequence, much Indigenous heritage practice in Australia has developed beyond compliance with the narrow confines of legislation, and the discipline now encompasses a broad perspective on past and present associations between Indigenous peoples and their culture (Smith 2006).

\section{Indigenous Participation in CHM}

Tertiary level education and training is a key requirement for professional advancement and effective practice in Australian CHM. The importance of tertiary qualifications for professional entry has been recognised by professional archaeology bodies and universities. A minimum of an honours degree or fourth year postgraduate degree in archaeology is required for membership of the key professional accrediting body, AACAI. This was also recognised in the 2008 publication By Degrees (Beck 2008), Australia's tertiary sector teaching benchmark, which aimed to close the gap between university training and professional practice identified in surveys (Ulm et al. 2005). Ulm et al.'s 2010 survey data show, however, that only $0.8 \%$ of respondents identify as Indigenous, down from $2.3 \%$ in 2005 (Ulm et al. 2013). While these survey data may suffer unduly from sample size bias, they demonstrate what many in the profession already know, namely that very few Indigenous Australians are engaged as professional practitioners within archaeology/CHM itself. Interestingly, this low figure contrasts with the fact that $66.4 \%$ of all work done by Australia's professional archaeology community focuses on the archaeology of Australia's Indigenous peoples (Ulm et al. 2013). This does not mean that Indigenous 
Australians are excluded from participation, as many work as community representatives, in most cases paid for their work, fulfilling legislative requirements for stakeholder consultation during development. However, it does illustrate that few Indigenous Australians participate as managers in CHM and the authors' experiences suggest that many take part with minimal professional training and few formal qualifications, although most have local training from Elders and other forms of traditional education and knowledge. The formation of the Australian Indigenous Archaeologists' Association (AIAA), with more than 20 qualified Indigenous archaeologists (Perry 2010), reinforces the fact that there are few Indigenous people with formal university-level qualifications. Low levels of professional qualification serve to limit the role of Indigenous people in CHM and, this may serves to constrain their earning capacity within this area of practice.

Australia's professional bodies and universities have long recognised this problem and have sought to increase recruitment of Indigenous people through a variety of initiatives, such as alternative pathway programmes to university entry, recognising prior learning, developing mentoring programmes for Indigenous students and supporting the attendance of community representatives and students at national conferences. Both professional surveys (Ulm et al. 2013) and anecdotal evidence suggest these mechanisms have failed to increase formal Indigenous participation in the profession. A key problem may be the well-recognised low participation rate of Indigenous Australians in tertiary education generally, which may form an effective barrier to their participation or progress in CHM careers. Although the reasons for such low tertiary education participation rates are multifaceted and complex, the Indigenous Higher Education Advisory Council (2008) identified poverty and related educational disadvantages, high attrition rates in secondary education and over-representation of Indigenous students in vocational studies at high school as key factors.

While comprehensive research data are lacking specifically to explain low participation rates in archaeology/CHM, several factors may be identified as a basis for discussion. Of great importance is the widespread lack of awareness concerning Australian archaeology and CHM issues in the wider community (Colley 2002; Nichols et al. 2005). Archaeology remains all but absent from the Australian school system-at both primary and secondary levels-beyond its somewhat out-of-date characterisation as a source of supporting data in classical/ Mediterranean ancient history (Nichols et al. 2005). While the new Australian Curriculum may correct this bias, there remains a widespread lack of knowledge concerning the subject amongst teachers and an absence of well-researched teaching materials outside the traditional fields and including Indigenous heritage.

\section{Internet-Based Solutions for Indigenous Outreach}

With its global reach, combined with increasing speed and capacity, the internet has completely transformed communications and accessibility to knowledge. For Australia's tertiary institutions, the internet has offered a new way to deliver courses and training to remote, rural and regional communities, many of whom are located long distances from the urban centres where campuses are usually situated. Much of that content is focused on income-generating award courses within the Australian Quality Framework (AQF), providing a range of accredited qualifications in degree or other formal study programmes. Information archives, especially those funded by public sources, and research/outreach projects are also increasingly being hosted on the web. A good example from regional Australia is the Gummingurru project, which incorporates traditional knowledge, archaeological research and resources for schools and community members (<http:// www.gummingurru.com.au/>; see also Ross et al. 2013). An area that has been less well explored by institutions is the provision of free-to-user, high quality training as part of community outreach capacity-building programmes, especially those targeted at disadvantaged groups who may otherwise have limited options for such training.

While the internet has opened up many new community outreach possibilities for educators, it also has the potential to improve both the access to, and the outcomes of, education and training for Indigenous Australians. Firstly, the internet is widely accessible. Contrary to widespread misconceptions, the majority of Indigenous Australians now live in cities or towns where access to the internet is efficient and effective. Access is also improving outside metropolitan areas, even in the most remote communities, with the national broadband strategy aiming to cover most of Australia with high speed internet access by 2020 . Computers are also widely available through public bodies, such as schools and public libraries, meaning that internet access is possible even for the most economically disadvantaged people. This means that internet delivery is a potentially effective means of providing an accessible training course in the home communities of Indigenous people without their needing to travel. Secondly, modes of delivery of curricula incorporating web-based materials have been shown to be effective in encouraging participation and retention of Indigenous students (e.g. York and Henderson 2003).

\section{Design Considerations}

While the internet was the obvious medium for an accessible course in CHM, careful consideration of the course design was required to make sure that it met the needs of both the educators and the user group. The overall aim of the course was to encapsulate the essence of professional best practice, as recognised in the Burra Charter (Australia ICOMOS 1999), to complement the existing knowledge that Indigenous course members brought with them to their study. In a nutshell, the approach emphasises broad-based stakeholder consultation as the basis for making CHM decisions, recognising the multiplicity of heritage values—scientific, aesthetic and cultural—that objects, sites and places may have. A landscape approach to CHM is emphasised in Keeping Country, a perspective strongly influenced by Australian archaeology's engagement with Indigenous communities who conceive that the natural world and cultural heritage are integrally linked (Bradley 2001, 2010; Kearney and Bradley 2006; McNiven 2008; Ross and Quandamooka 1996; Tamisari and Wallace 2006).

In line with best practice, a reference group of Indigenous stakeholders from the heritage sector in southeast Queensland was engaged to advise the project design team. The reference group was involved throughout the design stage, advising on the overall course structure, focus and content, as well as 
on contentious issues and contributing case studies to the course modules. The reference group was also fundamental in developing the name Keeping Country, which was chosen to reflect Indigenous approaches to managing their lands. The group also advised on the use of colour-specifically preferring ochre tones-and imagery used in the website banner and through the webpages. There was inevitably a geographical bias in expertise within the project team and reference group towards Qld. While that expertise was drawn on to provide some examples in the course modules, a wider frame of geographical reference was also included and it is considered to serve as an introduction to Australian CHM as a whole.

The course also had to be accessible. At the most fundamental level, this meant that the content had to be comprehensible to a non-specialist audience. The course also had to be cost-free to the user. Careful consideration was given to the time required to complete the course and, where necessary, content was trimmed so that each module could be finished in 60-90 minutes, depending on reading speed. Furthermore, a platform was required that allowed users to save their progress and exit at any time, allowing the course to be studied in an unhurried fashion scheduled around other commitments. A final, but important, consideration was download speed. While internet speed in urban areas is comparable to expected global standards, it rapidly falls away beyond Australia's urban areas, and many rural and remote areas have low broadband speeds, and sometimes unreliable access to internet services. Design thus attempted to maximise access in low bandwidth regions.

A core requirement was that the content of the course was of a high scholarly quality, meaning that it was reliable, accurate and relevant for the user group. After discussion it was agreed to base the course content on an existing undergraduate award course (details below) offered at The University of Queensland (UQ), abridged and rewritten in a style suited to the project aims. Use of the UQ name and logo on course materials reflects not only the institutional identity of the website host and principal designers, but also emphasises the quality of the course content. Assessment was deemed essential to demonstrate that graduates had achieved a uniform, minimum standard of course understanding. Provision of a personalised certificate of completion was also considered important, acting as both a reward to the graduates and providing a verified record of achievement. Finally, the course had to be easy to administer, requiring minimal time to train students in its use, as well as minimal designer input into ongoing maintenance and monitoring.

\section{Implementation}

After lengthy enquiry and discussion with online educators, Moodle <http://moodle.org/>, a widely used open source learning management system (LMS), was used to develop, manage and host the course. Moodle provided a flexible, effective, designer-friendly platform that allowed the course to be accessible to anyone in the global community and also had modules allowing all required design features to be pursued, including the provision of personalised certificates. UQ's existing Blackboard-based LMS could not be used in this way, as licensing conditions restrict access to persons formally enrolled in courses or on the staff list of UQ. Use of Moodle opened enrolment to anyone and meant that both enrolment and course administration was largely automated. Moodle's open source code and large international user and development group also bodes well for its future presence and sustainability.

Course content was based on a modified version of the undergraduate course LPWM2008 Cultural Heritage Management, taught in the Bachelor of Applied Science (Parks and Wildlife Management) and Bachelor of Environmental Management programmes at UQ, structured into five selfcontained modules, supplemented by supporting materials (Figure 1). Modules drew on Australian professional practice, as experienced by project members, supplemented by Australian and international open access research publications. While the course's content was based on an undergraduate tertiary course, it has to be emphasised that the content is introductory and does not provide a professional qualification in CHM. The aim of the course is ultimately to develop a better understanding of cultural heritage in the broader community and encourage an interest in formal study of CHM amongst people who may benefit from it. This is made clear in both the introductory materials and the certificate of completion (Figure 7). It should be noted that the course was not initially designed to align to the AQF and effort was focused on developing a working online, free-standing course within the design considerations discussed above.

Module 1, Introduction to cultural heritage and cultural heritage management, defines the area of study, providing definitions of culture and $\mathrm{CHM}$, and presenting a history of CHM in archaeology, including discussion of the Burra Charter (Australia ICOMOS 1999) on which contemporary practice is based (Pearson and Sullivan 1995; Sullivan 2004). Module 2, Heritage legislation, introduces state and federal legislation governing CHM in Australia and outlines the legal frameworks for how heritage places and objects are managed. Module 3, Documenting heritage places, introduces examples of the range of objects and places constituting heritage and demonstrates how their recording can be approached at the practical level, emphasising the limits of action for those lacking professional training. Module 4, Visitor management and cultural heritage interpretation, discusses how heritage places can be appropriately managed and interpreted to the public in a way that ensures the conservation of the values of the heritage places, with practical advice for communities. Module 5, Nature conservation, cultural landscapes and cultural heritage management, critiques the concept of 'wilderness' and discusses the problem of the potential conflict between natural and cultural values of landscapes and the management contestation that can result.

An essential part of course design has been the provision of adequate scaffolding so students can understand the course content, its components and how to use it. A welcome page forms the initial contact point for users and contains only a brief description of the course, with a link to a fuller introduction (see structure in Figure 1). The welcome page has been kept brief to be less off-putting to users and also to allow expansion of content should other courses be developed. The course page (Figure 2) is the central structuring element, allowing navigation through the modules via hyperlinks and indicating when modules and assessment are passed, and which modules are yet to be studied. Provision of brief module descriptions on this page and key learning objectives also provides a concise means of reviewing the course content. An extensive help page, 


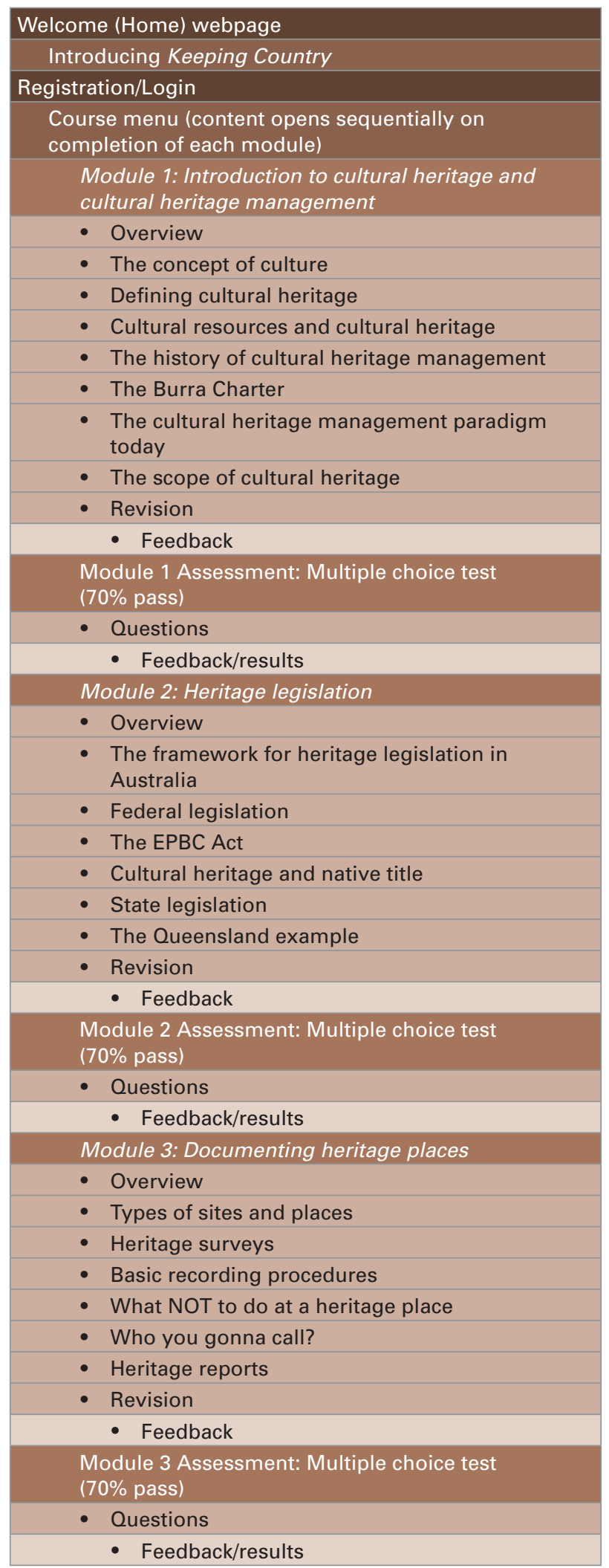

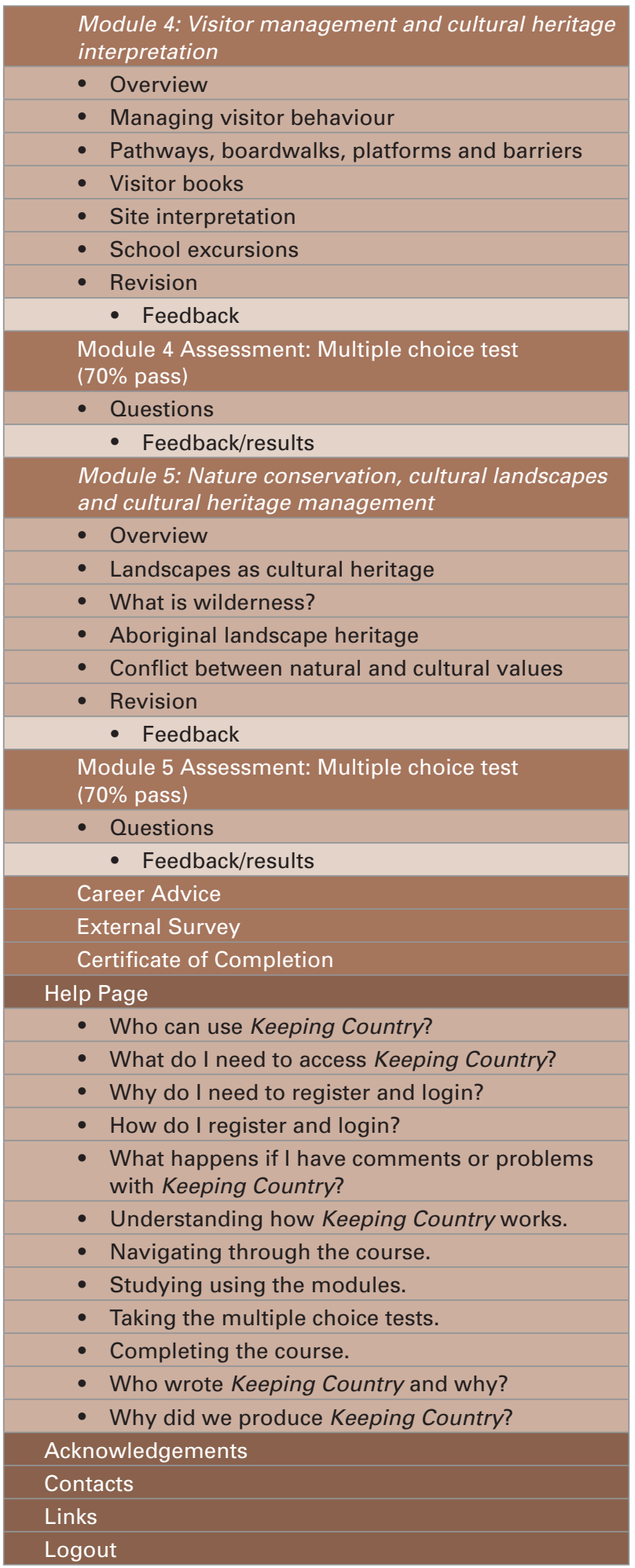

Figure 1 Keeping Country website structure. 
visible as a drop-down menu below the website header on each page (Figure 2), contains information on all aspects of the course, from rationale to navigation and taking the tests (see Figure 1). This was supplemented by a links page and may be appended with a glossary in the future.

Each module is structured into several separate webpages, each covering a key issue within the module (Figures 1 and 3). Separation of the modules in this way avoids lengthy and confronting pages of text, and helps to reduce download speed in the low-bandwidth areas. Higher download speeds are also achieved by minimising the number of large images in each of the pages and using hyperlinks to allow exploration of further pages containing supplementary information and larger images when they are necessary-for example photographs of heritage places (Figure 4). External content is also connected via hyperlinks, in some cases to words and in others to clickable maps and images (Figure 5). Plain English is used as much as possible and essential technical terms defined via hyperlinks or in the text.

Each module ends with a multiple choice test comprising ten questions, each with four possible answers (Figure 6). All are answerable with reference to the preceding text and can be accessed as many times as necessary to achieve the $70 \%(7 / 10)$ pass mark. Multiple choice questions in each run of the test are drawn randomly from a bank of 20 , allowing some variation in questions. To encourage study and completion of the test a revision section has been added to the end of each module's content (Figure 1). Revision modules open a series of questions from the relevant multiple choice bank and provide instant feedback on the answers given by the students.

Modules are designed to be completed sequentially, with a pass mark required in the concluding test for each module to enable access to the subsequent module. Modules can be navigated via the course page (Figure 2) and progress is automatically saved by the LMS, which requires individual registration and the maintenance of a database of users. Initially it was planned to have an essentially anonymous userbase, with users allowed any login, email and password without the need for inserting a name. This was designed to encourage full and forthright feedback by course graduates and also not to discourage those who may be suspicious of registration processes. However, the necessity for providing a personalised certificate meant that this approach to registration was not possible; the certificate requires both the name and location of students. Consequently, to facilitate anonymous feedback, the free online survey system Survey Monkey ${ }^{\circledR}$ has been used to host a survey (see Figure 8), accessible on the course page. The final elements of the course provide career advice and a downloadable certificate of completion (Figure 7). The latter is automatically generated from registration data and includes an explanation of the course and the date of completion.

Once the full functionality of Moodle was appreciated an educational designer rapidly developed the planned standalone, free-to-user, open-access web-based training course. The overall cost was AUD $\$ 31,000$, much of which was expended on employing an assistant to compile and edit the course materials, and liaise with the stakeholder group. Website design, including the banner and associated promotional materials, amounted to ca AUD\$6000, making Keeping Country a relatively inexpensive outreach initiative. Keeping Country was completed in December
2010 and can be accessed by anyone at $<$ http://www.uq.edu.au/ keepingcountry>.

\section{Discussion and Conclusion}

$\overline{\text { In developing Keeping Country the project team overcame some }}$ significant and unexpected problems, most significantly in identifying an appropriate LMS platform and integrating it into the institutional IT network at UQ. Having been set up to manage and access full award (i.e. degree/certificate/diploma) courses, the university's management systems could not be adapted to accommodate stand-alone, non-fee paying award courses aimed at the wider public. This was not just a technical problem. The project team had to overcome significant administrative hurdles and bureaucratic objections to enable the course to carry UQ's logo, use a palette of colours and banner outside the corporate template-as specified by the reference group—and be hosted on its website. Moodle was found to be easily adapted to the project's needs, easy to administer and capable of incorporating all the design elements. A problem identified by our Moodle educational designer was the sheer inefficiency of the design process, caused in part by the inexperience of the project team in designing complete courses for web delivery. Consultation with the designer before collating the project materials would have saved significant time and money.

Can the project be judged a success? From the project team's point of view, the site itself is a successful product. Technically it works, contains all the essential elements we feel are necessary for success and its maintenance is not a major imposition on our time. One internal criticism is that the strategies adopted to reduce download speed-namely minimisation of images on the main pages and reliance on hyperlinks to guide users to maps, photos etc.-led to pages dominated by text. It remains to be seen whether a focus on minimal size may be detrimental to the overall effectiveness and uptake of the course by our target group. And it is ultimately the uptake by, and effect on, that groupIndigenous Australians-that will determine whether Keeping Country is considered a success.

We plan to evaluate Keeping Country's success in two key areas. Firstly, to establish whether is it successful as a stand-alone course in meeting its pedagogical aims and providing an appealing, engaging and informative course that improves understanding of CHM amongst its students. Secondly, the course has to stimulate interest in continued participation of the students in CHM, especially through further study. The latter is especially important given the aims of this project. Both of these criteria are testable via the online survey that students are requested to complete on graduation, which includes questions relating to both course design and its effect on the students' engagement with CHM. Evaluation of the actual effects of this initiative in terms of its larger impact can only be assessed over the longer term and may be difficult, if not impossible, to formally evaluate by surveys etc., unless specific questions are included in future national surveys (i.e. Ulm et al. 2013). High student satisfaction with the course content and an indication that graduates have been encouraged to a greater interest in CHM and/or further study, will be taken as a sign of success in this approach to CHM teaching.

Survey responses-from both Indigenous and nonIndigenous respondents-and informal comments indicate that there is a generally positive view of the course and that 

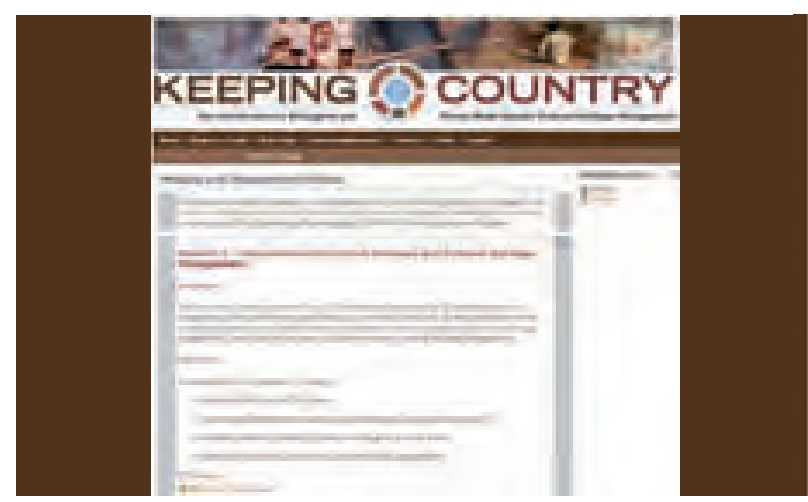

Figure 2 Course webpage which acts as the central navigation menu.

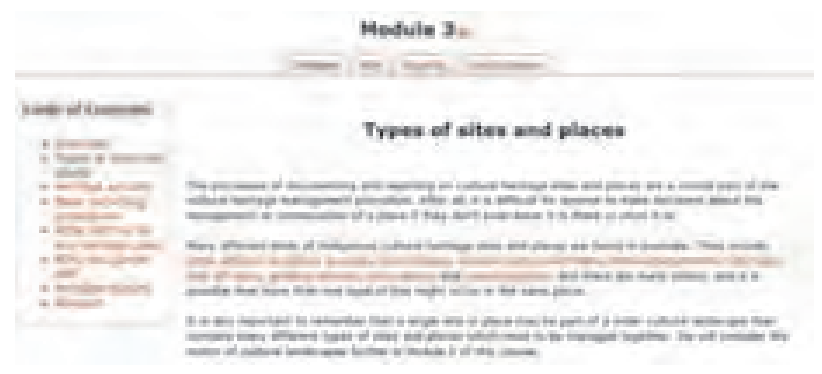

Figure 3 Module front webpage, showing menu of contents to left.

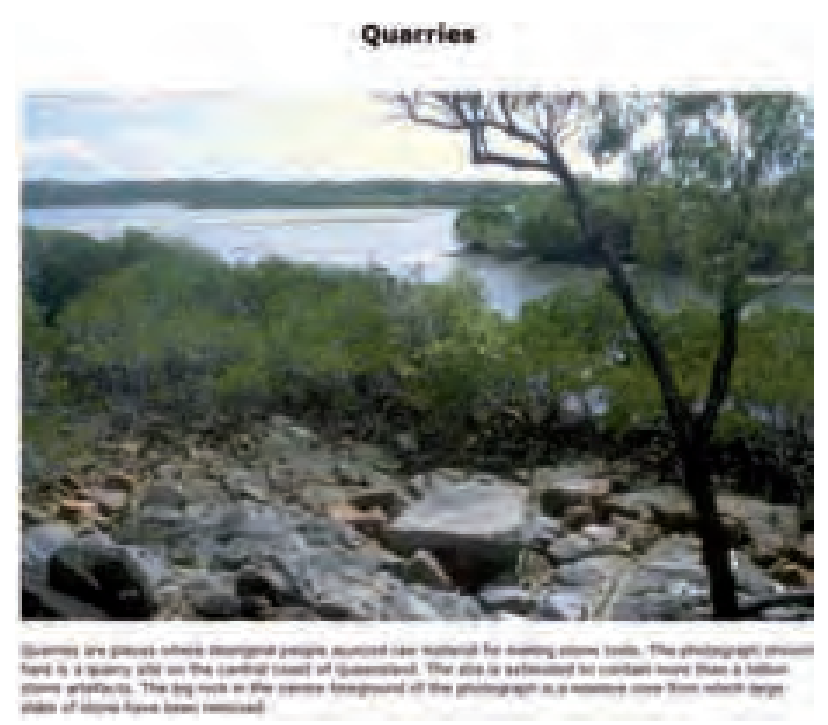

Figure 4 An example of a site type incorporating images and text hyperlinked to the module pages.

technical problems have not been encountered with its operation. There was some concern that the language was too technical in some places and requires rewording in plainer English. Positively, the course has been reported as increasing the respondents' knowledge of CHM and encouraging them to pursue $\mathrm{CHM}$ as an interest. The project team is currently promoting the course's use through its own network in Australia and one local community group in southeast Qld is interested in taking up the course for community training via its museum. A community in the Northern Territory is interested in developing a version of the course in their own language. While these possibilities are yet to come to reality, they demonstrate an appetite for online training by Indigenous Australians and

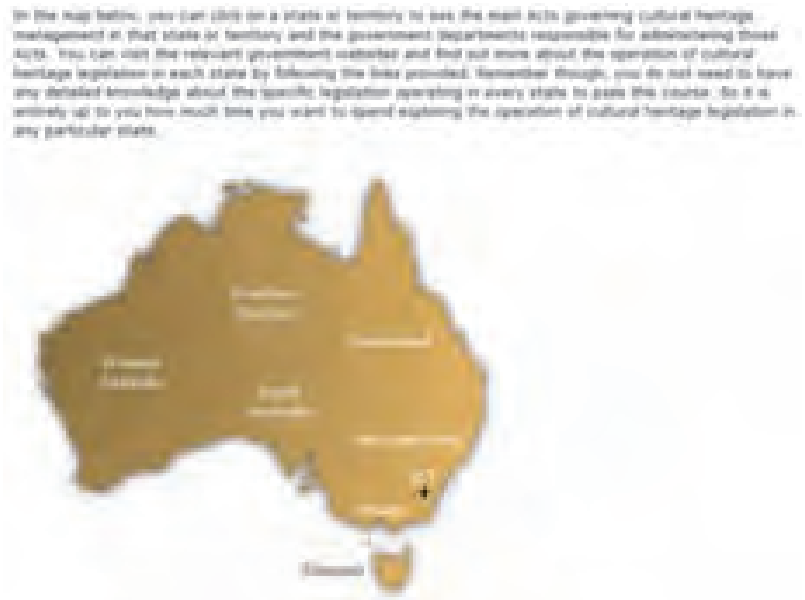

Figure 5 Clickable map linked to external web content.

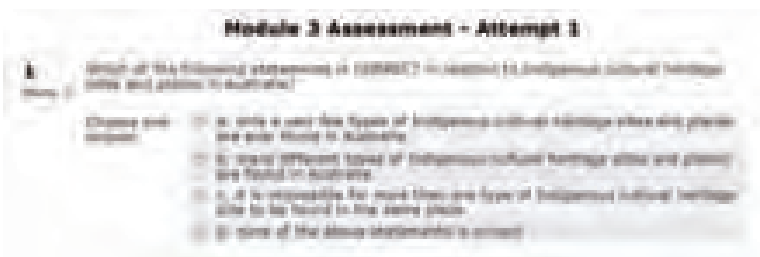

Figure 6 Example of a multiple choice question.

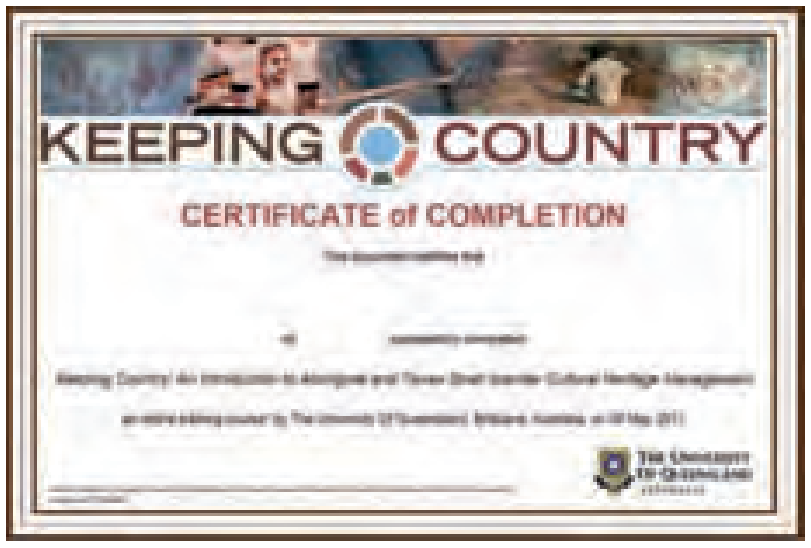

Figure 7 Personalised certificate of completion.

a willingness to embrace and experiment with new learning platforms. Reference group feedback is also shaping the first major revision of the course content, with several reference group members having suggested that the course should be fully aligned to the AQF, both to formally accredit its content and to encourage study by Indigenous participants.

In conclusion, a fully operational, self contained, free-to-user course in CHM, designed with and for the Indigenous Australian community has been designed and launched. Using open source software to overcome problems caused by institutional LMS access and specific design requirements, the package is now freely available to the world community and is being evaluated by a reference group. The response so far has been positive and formal surveys will allow the evaluation of the project's overall success in broadening interest in CHM in Indigenous communities and encouraging entry into further study through university and other institutions. The largerscale impact of this initiative may only be assessable in the longterm and through national level surveys. Whatever the impact of this particular course, the project has demonstrated that modest 


\section{Section 1: About you}

\begin{tabular}{|l|l|}
\hline $\begin{array}{l}\text { Do you identify as an Aboriginal and/or Torres Strait Islander } \\
\text { person? }\end{array}$ & Yes/No \\
\hline What is your sex? & Male/Female \\
\hline What is your age? & $16-90$ in 5 year increments \\
\hline What state or territory are you based in? & ACT, NSW, NT, QLD, SA, TAS, VIC, WA, Other (specify) \\
\hline \multirow{5}{*}{ What term best describes your location? } & $\square$ Capital City \\
\hline & $\square$ Regional Centre \\
\hline & $\square$ Rural Area \\
\hline & $\square$ Remote Area \\
\hline & $\square$ Other (specify) \\
\hline Which of the following statements describe you best? & $\square$ I am at School \\
\hline (please tick all applicable) & $\square$ I am at TAFE \\
\hline I have finished a TAFE course \\
\hline I am at university \\
\hline I have finished a university course \\
\hline I work in a field related to cultural heritage \\
\hline
\end{tabular}

\section{Section 2: Course evaluation}

A. Please indicate how strongly you agree with each of the following statements:

\begin{tabular}{|c|c|c|c|c|c|}
\hline Statement & $\begin{array}{c}\text { Strongly } \\
\text { Agree }\end{array}$ & Agree & Neutral & Disagree & $\begin{array}{l}\text { Strongly } \\
\text { Disagree }\end{array}$ \\
\hline \multicolumn{6}{|c|}{ The structure of the course made it easy for me to learn. } \\
\hline \multicolumn{6}{|c|}{ The content of the modules was easy to follow. } \\
\hline \multicolumn{6}{|c|}{ I sometimes found the terms used difficult to understand. } \\
\hline \multicolumn{6}{|l|}{ The multiple choice tests were too hard. } \\
\hline \multicolumn{6}{|l|}{ I found the format to be attractive. } \\
\hline The length of each module was too short. & & & & & \\
\hline
\end{tabular}

B. Yes/No answers with free form comments box:

- Are there any areas not covered in Keeping Country that you would like to see added?

- How could we improve Keeping Country?

- Did completing the Keeping Country course improve your knowledge of Aboriginal and Torres Strait Islander cultural heritage management?

- Will you recommend the Keeping Country course to others?

- After completing the Keeping Country course, are you now more interested in cultural heritage management and archaeology?

- Are you interested in pursuing further study in cultural heritage management and/or archaeology? Would you travel to another city to study?

- Are you interested in joining one of Australia's archaeological or cultural heritage associations?

- Do you have any other comments about any aspect of the Keeping Country course?

Figure 8 Keeping Country evaluation survey questions.

budgets and open access software can be used to mobilise specialist knowledge to produce stand-alone training programmes that have the potential to bridge university and community interests outside the standard award course frameworks.

\section{Acknowledgements}

Keeping Country was funded by a grant from the Higher Education Equity Support Program with financial contributions by Everick Heritage Consultants and The Culture and Heritage Unit, UQ. Other support came from the School of Social Science and the Aboriginal and Torres Strait Islander Studies Unit, both of UQ. The site was developed by Jason Grice, with design of the banner and marketing materials by LoveHate Design. Trevor Burke (UQ Office of Marketing and Communications) expertly negotiated UQ web services and Professor Debbie Terry provided key advice and support in the completion stages of the project. We also thank the Indigenous Reference Group, for their advice in all stages of the project. SU is the recipient of an Australian Research Council Future Fellowship (project number FT120100656).

\section{References}

Aitchison, K. and R. Edwards 2008 Archaeology Labour Market Intelligence: Profiling the Profession 2007-08. Reading: Institute of Field Archaeologists. 
Australia ICOMOS 1999 The Burra Charter. <http://australia.icomos.org/ publications/charters/>

Beck, W. (ed.) 2008 By Degrees: Benchmarking Archaeology Degrees in Australian Universities. Armidale: Teaching and Learning Centre, University of New England.

Bradley, J. 2001 Landscapes of the mind, landscapes of the spirit: Negotiating a sentient landscape. In R. Baker, J. Davies and E. Young (eds), Working on Country: Contemporary Indigenous Management of Australia's Lands and Coastal Regions, pp.295-307. Melbourne: Oxford University Press.

Bradley, J. with Yanyuwa families 2010 Singing Saltwater Country: Journey to the Songlines of Carpentaria. Melbourne: Allen and Unwin.

Byrne, D. 2005 Messages to Manilla. In I. Macfarlane, M.J. Mountain and R. Paton (eds), Many Exchanges: Archaeology, History, Community and the Work of Isabel McBryde, pp.53-62. Aboriginal History Monograph 11. Canberra: Aboriginal History.

Colley, S. 2002 Uncovering Australia: Archaeology, Indigenous People and the Public. Sydney: Allen and Unwin.

Colley, S. 2003 Lessons for the profession: Teaching archaeological practical work skills to university students. Australian Archaeology 57:90-97.

Colley, S. 2004 University-based archaeology teaching and learning and professionalism in Australia. World Archaeology 36(2):189-202.

Colley, S. and S. Ulm 2005 Teaching, learning and Australian archaeology. Australian Archaeology 61:7-10.

Ellis, B. 1994 Rethinking the Paradigm: Cultural Heritage Management in Queensland. Ngulaig Monograph Series 10. Brisbane: Aboriginal and Torres Strait Islander Studies Unit, The University of Queensland.

Fourmile, H. 1996 The law of the land: Whose law? Whose land? In L. Smith and A. Clarke (eds), Issues in Management Archaeology, pp.45-50. Tempus 5. St Lucia: Anthropology Museum, The University of Queensland.

Godwin, L. 2005 'Everyday archaeology': Archaeological heritage management and its relationship to native title in development-related processes. Australian Aboriginal Studies 2005(1):74-82.

Godwin, L. and J. Weiner 2006 Footprints of the ancestors: The convergence of anthropological and archaeological perspectives in contemporary Aboriginal heritage studies. In B. David, B. Barker and I.J. McNiven (eds), The Social Archaeology of Australian Indigenous Societies, pp.24-38. Canberra: Aboriginal Studies Press.

Hiscock, P. 2008 The Archaeology of Ancient Australia. London: Routledge.

Indigenous Higher Education Advisory Council 2008 Submission to the Review of Australian Higher Education. <http://www.deewr.gov.au/Indigenous/ HigherEducation/Programs/IHEAC/Documents/HER.pdf>

Kearney, A. and J. Bradley 2006 Landscapes with shadows of once living people: The Kundawira challenge. In B. David, B. Barker and I.J. McNiven (eds), The Social Archaeology of Australian Indigenous Societies, pp.182-203. Canberra: Aboriginal Studies Press.

King, T.F. 2003 Places that Count: Traditional Cultural Properties in Cultural Resource Management. Walnut Creek: AltaMira Press.

Langford, R. 1983 Our heritage - your playground. Australian Archaeology 16:1-6. Makagiansar, M. 1989 The work of UNESCO. In L.V. Prott and J. Specht (eds), Protection or Plunder? Safeguarding the Future of our Cultural Heritage, pp.9-
13. Canberra: Australian Heritage Commission for UNESCO and Australian Government Publishing Service.

McNiven, I.J. 2008 Sentient sea: Seascapes as spiritscapes. In B. David and J. Thomas (eds), Handbook of Landscape Archaeology, pp.149-157. Walnut Creek: Left Coast Press.

Nichols, S. 2011 Public or Perish: An Ethnographic Study of Archaeology in a Southeast Queensland Community. Unpublished PhD thesis, School of Social Science, The University of Queensland, St Lucia.

Nichols, S., J. Prangnell and M. Haslam 2005 Hearts and minds: Public archaeology and the Queensland school curriculum. Australian Archaeology 61:71-79.

Pearson, M. and S. Sullivan 1995 Looking after Heritage Places: The Basics of Heritage Planning for Managers, Landowners and Administrators. Melbourne: Melbourne University Press.

Perry, N. 2010 Indigenous archaeologists launch new group. $<$ http://news.ninemsn. com.au/national/8180585/indigenous-archaeologists-launch-new-group >

Prangnell, J., A. Ross and B. Coghill 2010 Power relations and community involvement in landscape-based cultural heritage management practice: An Australian case study. International Journal of Heritage Studies 16(1-2):141155.

Ross, A. 2010 Defining cultural heritage at Gummingurru, Queensland, Australia. In H.Allen and C. Phillips (eds), Bridging the Divide: Indigenous Communities and Archaeology into the 21st Century, pp.101-124. Walnut Creek: Left Coast Press.

Ross, A. and Quandamooka Land Council 1996 Aboriginal approaches to cultural heritage management: A Quandamooka case study. In S. Ulm, I. Lilley and A. Ross (eds), Australian Archaeology '95: Proceedings of the 1995 Australian Archaeological Association Annual Conference, pp.107-112. Tempus 6. St Lucia: Anthropology Museum, The University of Queensland.

Ross, A., J. Prangnell and B. Coghill 2010 Archaeology, cultural landscapes and Indigenous knowledge in Australian cultural heritage management legislation and practice. Heritage Management 3(1):73-96.

Ross, A., S. Ulm and B. Tobane 2013 Gummingurru - A community archaeology knowledge journey. Australian Archaeology 76:62-68.

Smith, L. 2006 Uses of Heritage. New York: Routledge.

Sullivan, S. 2004 Aboriginal sites and the Burra Charter. Historic Environment 18(1):37-39.

Tamisari, F. and J. Wallace 2006 Towards an experimental archaeology of place: From location to situation through the body. In B. David, B. Barker and I.J. McNiven (eds), The Social Archaeology of Australian Indigenous Societies, pp.203-223. Canberra: Aboriginal Studies Press.

Ulm, S., G. Mate, C. Dalley and S. Nichols 2013 A working profile: The changing face of professional archaeology in Australia. Australian Archaeology 76:34-43.

Ulm, S., S. Nichols and C. Dalley 2005 Mapping the shape of contemporary Australian archaeology: Implications for archaeology teaching and learning. Australian Archaeology 61:11-23.

York, F.A. and L. Henderson 2003 Making it possible: The evolution of RATEP—a community-based teacher education program for Indigenous peoples. The Australian Journal of Indigenous Education 32:77-84.

Zeder, M.A. 1997 The American Archaeologist: A Profile. Walnut Creek: Altamira Press. 